\title{
Designing Mobile Service Experiences, the Role of Emotional Dimension*
}

\author{
Teresa Sarmento \\ Faculdade de Engenharia da Universidade do Porto \\ Rua Dr. Roberto Frias, s/n 4200-465 Porto, Portugal \\ teresasarmento@esad.pt
}

\begin{abstract}
This research project aims to improve the methods for translating emotional factors experienced by users into characteristics of the mobile service interfaces.
\end{abstract}

Keywords: service design, user experience, mobile interfaces, new services, service experience prototyping.

\section{Motivation}

The mobile phone is undoubtedly a powerful tool to connectivity and many other functions; it's like a Swiss army knife $[1,2]$, and goes far ahead of voice communication The Portuguese mobile phone network reaches 12,2 millions of subscribers with a $115,7 \%$ penetration rate[3]. This widespread use of mobile phones has created a huge opportunity for service providers [4], and many companies, such as banks and retailers, now offer their services through mobile networks. But to develop successful mobile services, it is important to understand customer experience requirements and to carefully design the service experience desired by customers. As the new world of opportunities for mobile services has emerged we need to classify elements connected with the interest in mobile phones and their services supporting the co-creation of value through the dedicated design of new particular and interactive applications, interfaces and its specific mobility[5]. In addition to improving core technologies, they must also focus on providing a rich and satisfying mobile-communication experience to end users [6]. The intentions of using mobile services go beyond the technology acceptance model and Herbjon Nysveen et al $[7,8]$ conclude, from their cross comparison study, that it depends on the service characteristics and the value of its perceived expressiveness.

In this context, it is of the greatest importance to understand user's emotional and experiential behavior[9]. In addition to improving core technologies, developers must focus on providing end users a rich and satisfying mobile-communication experience.

\footnotetext{
* Advisors: Lia Patricio and José Bartolo.
} 


\subsection{Literature Review and New Challenges Raised by Mobile Service Design}

User experiences are very important for mobile service success, as the context of use and conditions are constantly and rapidly changing. However, service experiences and especially mobile service experiences need further research as referred by Manfred Thüring [2] factors such as aesthetic qualities and emotional experiences play an important role in addition to instrumental aspects and as he concludes further research topics concern the temporal characteristics of human-technology interaction and further dimensions of non instrumental qualities offer demanding opportunities to reach beyond 'classical' usability approaches.

Other previous studies [10] confirmed that emotional value and customer satisfaction affect mobile service experiences. Accordingly methods for translating user experience factors into service design require additional research. It is also recognized that service design requires interdisciplinary competences. The inter-disciplinary research can access research proposals more consistently and close partnerships with industry can help academics to develop relevant research agenda leading to interdisciplinary tools, models and frameworks [11] requiring the joint contribution of new service development, Interaction design, engineering

At this point, sketching and prototyping the service experience deserves particular attention[12]. Due to the distinctive characteristics of services (particularly intangibility and co-creation of value), prototyping services is quite different from prototyping products (the service tools and physical environment, but also the service process and the people, both customers and service employees). Several research frameworks can be useful, such as IDEO experience prototyping [13]or the service theatre framework [14]. However, a systematic approach to service experience prototyping is still lacking.

\section{Research Questions}

a. What are the most important experience factors that contribute to satisfaction and usage of mobile services?

b. How can these experience factors be translated into mobile service design? In particular, how can these experience factors be translated into the different components of a service experience prototyping?

c. What should be the components of a service experience prototype and how do they contribute to a better mobile service design and its testing?

\section{Method}

Empirical ground - the research project will involve joint work with a company which is developing a new mobile service, and comprises two main activities: the study of mobile service experiences and the development of new mobile service experience prototypes, through which new methods will be developed and tested.

Study of mobile service experiences: Through a framework of an iterative evaluation of the mobile service design, it is expected to access experiential factors and to refine them along its development and test its sequential releases. It will start with an 
exploratory study with a first set of interviews and observation of mobile service users to iterative walkthroughs and a survey. The research will make use in addition from a developer's point of view of several different techniques from sketching to paper prototyping and simulations in order to evaluate a longitudinal progression of the method.

Development of new methods for translating experience factors into mobile service design, through service experience prototyping. Along the new mobile service project, several releases will be iteratively developed, and several service experience prototypes will be created to translate experience factors. This iterative process will also allow for a systematic analysis of how the different service prototype components can contribute for to better user testing, better service design, and better results of the overall project.

\section{Expected Research Contributions}

Considering it as important to prototype the interface as it is to prototype the context of interaction, this research project will pursue a relationship between the service experience and service design through:

a. Better understanding of user experience factors in mobile services, identifying the factors and understanding how they impact customer satisfaction and usage of these services. Moreover, it will be interesting to understand how experience factors of mobile services differ from experience factors for of regular services.

b. Improvement and development of new methods for translating experience factors into service design, in particular for improving service experience prototyping.

\section{References}

1. Ballard, B.: Designing the Mobile User Experience. John Wiley \& Sons, West Sussex (2007)

2. Thüring, M., Mahlke, S.: Usability, aesthetics and emotions in human-technology. International Journal of Psychology 42(4), 253-264 (2007)

3. ANACOM, A.N.d.C.: http: / /www . anaco.pt (2008)

4. Jones, M., Marsden, G.: Mobile Interaction Design. John Wiley \& Sons, Ltd., West Sussex (2006)

5. Moggridge, B.: Designing Interactions. The MIT Press, Massachusetts (2007)

6. Subramanya, R.S., Yi, B.K.: Enhancing the user experience in mobile phones. Computer, 114-117 (2007)

7. Herbjon Nysveen, P.E.P., Thorbjornsen, H.: Intentions to use Mobile services: Antecedents and cross-service comparisons. Journal of the Academy of Marketing Science 33, 330-346 (2005)

8. Davis, F.D.: Perceived Usefulness, Perceived ease of use, and user acceptance of Information Technology. Mis Quarterly 13, 319-340 (1989) 
9. Norman, D.: Emotional Design - Why we love or hate everyday things. Basic Books, New York (2004)

10. Lim, H., Widdows, R., Park, J.: M-loyalty: winning strategies for mobile carriers. Journal of Consumer Marketing 23/4, 208-218 (2006)

11. Cambridge University, I.: Succeeding through Service Innovation, Developing a Service Perspective on Economic Growth and Prosperity. In: Cambridge Service Science, Management and Engineering Symposium, Cambridge UK (2007)

12. Buxton, B.: Sketching User Experiences. Morgan Kaufmann, San Francisco (2007)

13. Buchenau, M., Suri, J.F.: Experience Prototyping. In: DIS 2000. ACM, Brooklyn (2000)

14. Fisk, R.P., Grove, S.J., John, J.: Interactive Services Marketing. Houghton Mifflin Company, Boston (2008) 